\title{
Meaningful contexts or dead mock reality: which form will the everyday take?
}

\author{
Godfrey Sethole \\ Tshwane University of Technology (Ga-rankuwa) \\ email: sethole@hotmail.com
}

This paper describes the experiences of two teachers, Bulelwa and Kevin, who attempt to take on board the notion of incorporating the everyday into the mathematics, as the new South African Curriculum requires. Both of them, though in different ways, attempt to accommodate the two discourses, namely mathematics and the everyday. Because of their own different experiences and the different values they place on the everyday in mathematics, they handle the incorporation of the everyday quite differently. The paper argues that the practical experiences of these teachers provide insight into some of the practical challenges teachers have to negotiate in order to provide legitimacy for the everyday in mathematics.

The definition of mathematics in the new South African Curriculum, Curriculum 2005 ${ }^{1}$ (C2005), entails both an epistemological (what mathematics is) and pedagogical (how mathematics should be taught) position. It states (2001:16):

Mathematics has its own specialised language that uses symbols and notations for describing numerical, geometric and graphical relations. Mathematical ideas and concepts build on one another to create a coherent whole.

While sound mathematical development is very important, this Learning Area Statement recognises that access to Mathematics is a human right in itself, and it is not value or culture-free. In teaching Mathematics, try to incorporate contexts that can build awareness of human rights, and social, economic and environmental issues relevant and appropriate to the learners' realities.

The epistemological position, in the first paragraph of this definition, foregrounds mathematics as a unique and distinct entity. In Bernstein's (1996) terms, this definition puts mathematics in a "closed" relationship with other subjects. The pedagogical position, in the second paragraph, clearly addresses the

1 The South African government's plan was to phase in the new curriculum gradually. It was hoped that by the year 2005 every grade at school level would be implementing the new curriculum, hence the name 2005. teaching approach. It prioritises an approach to mathematics teaching which is compatible with a realistic approach. Thus, whilst mathematics remains a uniquely distinct entity, the non-mathematical everyday realities may be used as platforms to access it.

There is an acknowledgement, however, that incorporating the everyday in mathematics may derail mathematical goals and therefore should be treated “judicially” (Taylor and Vinjevold, 1999:116). This argument is central to Skovsmose's notion of "mathematical archaeology" (1994) and Adler's (2000) elaboration of the concept of transparency. Skovsmose (1994:94) admits that "mathematics may be integrated to such a degree that it disappears for both the children and the teachers. Then it becomes important that time is spent on getting hold of the imbedded competence. Mathematics has to be recognised and named and, that is the task of mathematical archaeology." In analysing Lave and Wenger's notion of transparency, Adler (2000:214) argues that "resources in schools need to be seen to be used (visible) and seen through to illuminate mathematics." If context is considered a resource in a mathematics classroom, then Adler's suggestion is that context is beneficial, provided it does not distract learners from mathematics.

This paper cites and reflects on the experiences of two Grade 8 mathematics teachers, Bulelwa and Kevin ${ }^{2}$. Kevin and Bulelwa teach in two different schools, in different contexts and settings, and handle

2 Bulelwa and Kevin are not teachers' real names 


\section{Godfrey Sethole}

the expectation of using context to teach mathematics quite differently. In particular, the paper aims to:

1. Highlight the different ways in which they handle the expectation of using contexts to teach mathematics.

2. Reflect on the reasons they handle the contexts (in the teaching of mathematics) in they way they do.

In conclusion, the paper will argue that the experiences of Bulelwa and Kevin provide us with insights into the practical challenges of incorporating these two different discourses, namely the everyday and mathematics.

Bulelwa and Kevin were participants in a bigger international project, the Learners' Perspectives Study (LPS). An outline of this study provides the broader context for this paper.

\section{The Learners' Perspective Study}

The Learners' Perspective Study is an international study which drew participation from ten countries, including South Africa. As the name suggests, the main aim/focus of the study was to document the learners' experiences of well-taught lessons. Each country was to document learners' experiences in three different schools at grade 8 level (Clarke, 2001:05). Because it was the experience of well-taught classrooms which was of interest, the major task was to identify schools with "good" mathematics teachers at grade 8 level. Good teachers are those who are considered reputable and efficient by the school community (the principal, colleagues and students) as well as other mathematics teachers in the area.

In South Africa, data collection took place from March 2001 to May 2002 in three grade 8 classes located around Durban, in the province of KwazuluNatal. The demographic profiles of the three schools differed significantly: one school was predominantly Indian, another predominantly African and the third school predominantly White. The decision to focus on three good teachers of different racial backgrounds was a deliberate one. It was motivated by the desire to observe the way in which teachers working in different cultural settings take up the challenge of implementing C2005.

Each data collection session entailed videotaping at least ten consecutive grade 8 mathematics lessons for a period of three weeks. For each school, we (as researchers) focused on one grade 8 classroom and therefore one teacher. Each lesson was followed by a post-lesson interview with a focus group (normally a group of 4 -6 learners) for that particular day. After each data collection session (i.e. at the end of a three week period) each of the teachers was interviewed. It is within this context that the teachers' views were accessed.

This paper draws on data collected at two of the three schools, a predominantly African and predominantly White school. Bulelwa, who teaches in a predominantly African, school holds a Bachelor of Science degree with Maths and Statistics as majors and a postgraduate Diploma in Education. The school is electrified, has a photocopying machine and a tidy reception area. For a township school, this school is fairly well-resourced and stands in contrast with the shacks in the school's neighbourhood. Kevin holds a four-year teaching Diploma with mathematics as major. His first language is English and he teaches in a predominantly white school located in a fairly quiet suburb. The school is electrified and has a photocopying room and a fully equipped computer laboratory with about thirty monitors. Access into the school is controlled; the school clerk has a clear view of the gate and can open it from her office.

The next section focuses on some of the local and international debates in relation to the incorporation of the everyday into mathematics as well as the theoretical framework I used to make sense of the data.

\section{Summoning the non-mathematics into and for mathematics}

To illustrate the seriousness of tensions within the mathematics community relating to the merits and demerits of the realistic approach, Cooper and Dunne (2000:07) admit: "We know already, as a result of responses to our work at conferences, that there will be a few individuals within the world of mathematics education who will wish that we had not produced this account of the difficulties children experience with 'realistic' items ... At worst, they may have a commitment to the merits of 'relevant' and 'realistic' school mathematics, ... More acceptably, they may fear that those demanding a return to a regime emphasising rote learning ... may find support in the work reported here.” A large body of literature, highlighting both the benefits and the limitations of using the everyday in mathematics, has amassed in recent years. The following section cites and reflects on some of the literature. 
Benefits and limitations of the realistic approach Skovsmose is amongst a number of mathematics educators who sees merit in incorporating the everyday into mathematics. In developing a critical mathematics philosophy, Skovsmose (1994) regards mathemacy as an integrated competence. To this end, he argues that the mathematics curriculum cannot be constituted by making reference to mathematics only. Freudenthal (1973), whose main thrust is in the teaching of mathematics, asserts that mathematics is too important to frame its instruction to suit the needs of the mathematicians. Freudenthal maintains that "meaningful contexts that are not exercised daily are as easily forgotten as mathematics or even faster." (1979:73). Recently Mukhupadhay (1998) highlighted a classroom experience in which a mathematical task led to a reflection on an everyday aspect. Adult learners were required to sketch an equivalent of a popular doll, Barbie, according to real-life scale. On completing the task, all groups suggested that real life Barbie was unreal and unnatural, with a pelvic area way too small to bear a child. Mukhupadyai argues that this exercise validates the usefulness of school mathematics beyond the usual abstract and contextempty existence. Though the studies and debates above are argued from different perspectives, they all tend to support the inclusion of the everyday into mathematics.

In South Africa, a number of scholars have registered their discomfort with a teaching approach which favours the inclusion of the everyday in school mathematics (See, for example, Taylor \& Vinjevold, 1999:113; Muller \& Taylor, 1985:17; C2005 Review report, 2000:37). Others are fairly critical but sympathetic (for example, Volmink, 1993; Vithal, 1997; Nyabanyaba, 1999)

Arguments against the inclusion of the everyday in school mathematics, or which suggests that such an action is insignificant in relation to the way learners engage with mathematics, have also been cited. Floden et al (1987), for example, are quite unambiguous in their criticism of incorporating the everyday into mathematics. They suggest that the everyday restricts the students' scope of vision and exaggerates reliability of close-to-home experience in the learning of mathematics which makes it difficult for learners to understand the academic disciplines. Saljo and Wynhamn (1993) conclude from their study that the influence of the everyday in mathematics is insignificant. They challenged 332 Swedish students to determine the cost of posting a letter on the basis of the official table of postage rates from the Swedish post office. The results of their study suggest that the task is interpreted as a mathematics task in a mathematics classroom and as a non-mathematical task in a social studies classroom (1993:332), rendering the incorporation of "relevant" data insignificant. This selective and situation-laden way of interpreting data is detectable in Cooper and Dunne's study as well. They note that one middle-class child treats realistic tasks presented to her as "...merely differently presented exemplars of standard arithmetic problems." The inclusion of the everyday for this child does not evoke an "everyday" response. In spite of its everyday nature, the task is still seen as a mathematical task. The common thread amongst these studies is a position which suggests that the boundary between mathematics and the everyday is significant and cannot be traversed easily in the learning of mathematics.

Bulelwa and Kevin are two teachers who attempt to manage an expectation of incorporating the everyday into mathematics. The nature of the tasks they use suggests their views on the role and value of the everyday in mathematics. Paul Dowling's (1998) notion of mythology provides a language and lens through which to engage with the mathematics everyday relationship. He asserts that the particular ways in which mathematics and other practices relate produces a set of myths. To this end, Dowling (1998:02) maintains that mythology is a result of "particular forms of realisation between the mathematical and other practices". Two of the six myths he cites are particularly useful for my current discussion, namely the myth of reference and the myth of participation.

\section{The myth of reference and the myth of participation}

The myth of reference entails a belief that mathematics is a place-holder for or "refers" to the non-mathematical. It recognises mathematics as a different activity to non-mathematical, everyday practices. In incorporating non-mathematics into mathematics, the non-mathematics is pruned off its other details, noise or "substantial residue of the nonmathematical” (Dowling, 1998:08). As Dowling suggests, "In its pure, ideal-type form, the myth of reference consumes the non-mathematical setting within a mathematical play leaving only a trace to remind us that there is something outside of mathematics" (1998:16). Thus, the myth of reference 


\section{Godfrey Sethole}

is characterised by mathematical tasks which are conveniently covered by a veneer of the everyday. Thus mathematics is presented "disguised" as if it is about a particular practice and not itself.

The myth of participation entails a belief that mathematics is a tool needed to engage in the everyday. In order for an individual to participate fully in a practice or a culture, mathematics is a necessity. In this respect, Dowling (1998:16) maintains: "This is precisely the nature of the myth: the claim to unity of culture which is, thereby, incomplete without the mathematics." In brief, mathematics is a ticket to participation.

This myth is characterised by school activities which foreground the non-mathematical and limits the explicit references to mathematics. Thus, these activities appear as genuine and meaningful practices, with a "high modality of the non-mathematical." As Dowling suggests, the myth of participation constructs mathematics as a "reservoir of use-values."

In drawing a distinction between the two myths, Dowling observes that the myth of participation, like a tool, is for something else; unlike the myth of reference, in which mathematics is about something else (my emphasis).

\section{Bulelwa: Foregrounding the social concerns over the maths skills}

Even though my colleagues and I observed and videotaped thirteen lessons in Bulelwa's class, our main focus for the interview drew mainly from a lesson in which she had used AIDS as a context for teaching number patterns. In teaching this section, Bulelwa set the scene by introducing a general discussion about AIDS. During this discussion, she advised the learners to practise safe sex because AIDS is real.
The main aim of her lesson, as she explained to the learners, was to highlight the relevance and applicability of mathematics in real life situations. Below is part of the worksheet that Bulelwa had given to the learners.

Her seven-item worksheet, which she had given to the learners the previous week, consisted of tasks that required them to engage, describe and communicate mathematical observations. For example, item (a) read as follows:

\section{Describe the pattern of population increase every forty} years as shown in the first table.

There were also questions that required learners to draw on their everyday experiences, for example item (g), which read:

What can we do as a society to break the pattern of the increasing number of AIDS sufferers (i.e. decrease the number of AIDS sufferers)?

Regarding this worksheet, the following two observations need to be highlighted:

AIDS as a context: KwaZulu Natal, the province in which this school is located, was once reported to have the highest infection rate of the HIV-virus. Even closer to the school, an AIDS activist in a neighbouring township, Gugu Dlamini, was beaten to death following her public declaration of her HIVpositive status. At a national level, President Thabo Mbeki has also faced a lot of criticism and negative publicity following his "unconventional" views about the cause and the prevention of AIDS. The details pertaining to these debates are well beyond the scope of this paper. The main point to tease out, though, is that AIDS, even as a context to advance mathematics

Mathematicians have studied number patterns for many years. It was discovered that there are links between mathematics and our natural environment and sometimes events occurring in our societies. For this reason an understanding of algebra is central to using mathematics is setting up models of real life situations.

Study the tables given and answer the questions that follow.

\begin{tabular}{|l|l|l|l|l|l|}
\hline Year & 1960 & 2000 & 2040 & 2080 & 2120 \\
\hline World population growth & $\begin{array}{l}3000 \\
\text { million }\end{array}$ & $\begin{array}{l}6000 \\
\text { million }\end{array}$ & $\begin{array}{l}12000 \\
\text { million }\end{array}$ & & \\
\hline Year & 1997 & 1998 & 1999 & 2000 & 2001 \\
\hline World increase in the number of AIDS sufferers & $\begin{array}{l}16,7 \\
\text { million }\end{array}$ & $\begin{array}{l}33,4 \\
\text { million }\end{array}$ & $\begin{array}{l}66,8 \\
\text { million }\end{array}$ & & \\
\hline
\end{tabular}


is not a playful reality or benign issue. It is a sensitive and emotional socio-political issue.

The mode of expression: The mode of expression or the tone used to communicate the text to the reader does not bracket out the non-mathematicians. The letters and expressions which characterise mathematics are absent.

The task makes no explicit reference to specialised mathematical knowledge. Instead, it is presented as a genuine and meaningful activity in which mathematics will be a necessary tool. In this case, the incorporation of the everyday into mathematics yields a myth of participation (Dowling, 1988). In other words, mathematics is a prerequisite for predicting the number of AIDS sufferers in years to come.

In contrast, Bulelwa felt that she was prioritising the mathematics, and the context of AIDS, however useful, was meant to be a vehicle. For example, when our colleague Renuka asked why she chose AIDS as a context, she responded:

Bulelwa: Well, actually it was still number patterns. I wanted to choose something connected to real life. It's not that we learn mathematics in isolation. Just like when we started, we had an outbreak of cholera. I brought some statistics from the department; you know...the actual statistics from the department. So I taught them at the time how to get a table, a statistical table and analyse information. So it was learning mathematics, but with something that was happening at the time.

Renuka: How did you feel about the whole issue of mathematics and context? Did you feel that there was one which you were prioritising?

Bulelwa: I felt I was prioritising mathematics because most of the questions I asked were of a mathematics nature except the last two questions... "How it was transmitted" and " What can we do?" Because obviously if doing a lesson in class and the OBE context it need not just end up in a classroom situation. If you are dealing with the situation like this you need also to go out into the communities. So what I found out is that they (the learners) had more knowledge on AIDS...that they could handle most of the questions. That's why it was difficult for them to handle a question that was long.
It is clear that Bulelwa is conscious of the mathematical purpose of the lesson. Yet, her choice of AIDS as a context was not arbitrary; she was equally conscious of her role as an "advisor" to the learners. Her personal experience, in which a cultural practice and lack of knowledge about the transmission of HIV virus led to an unfortunate consequence, was related during the interview.

Bulelwa: Even more so when it comes to our tradition as Africans where we use traditional healing methods. Because that's where most of our communities have been hurt. Because you'll find yourself....that it is a true story where you find that the whole family has been wiped out. You know, mother, father, and grown up kids. You know I am not talking about small kids ...(looks for words)

Renuka: (finds the words) Oh yes...who were born with AIDS.

Bulelwa: Yes, I am talking about kids in their 20's and 30's. Now you ask yourself, "How can the whole family be wiped out?". And I know of two families. But when you follow the story you find that one family member had HIV, but now because it was our custom and tradition that from time to time we call a traditional healer, ...so maybe when things are not going well and you use traditional methods of healing - so part of it is to use a razor and cut....

Renuka: (Impulsive comment) Yes, it is the first time I learnt about it and I found it quite interesting.

Bulelwa: Yes and it did not come from me, it came from the kids themselves. They know...

Renuka: So the main problem was that if every member of the family was sharing the same blade then it was transmitted like that.

It is notable that Bulelwa is enacting two different and perhaps competing identities within the same lesson. She has a "shifting identity" (Setati, 2002:48). On the one hand, she is a mathematics teacher whose aim is to encourage a particular mathematical agenda: number patterns. On the other hand, she is a responsible citizen who wishes to alert the learners to AIDS and its effects, as the new curriculum advises. Could it be, though, that she is trading the mathematical skills for the social concerns? 


\section{Godfrey Sethole}

\section{Kevin: Foregrounding maths skills over social concerns?}

During our three week visit at his school, Kevin treated two sections, word problems and geometry. In setting the scene for the lesson on word problems, Kevin highlighted to the learners that the lesson was aimed at using mathematics to solve real-life problems. He actually formulated his own examples using the names of some of the learners in class.

Like Bulelwa, Kevin had compiled the tasks for the learners on a worksheet, which each learner was in possession of. The type of tasks Kevin had compiled are what Freudenthal (1973) refer to as "dead mock reality." These are tasks whose context is obviously fictional. As stated before, the new policy favours the use of meaningful, realistic examples; however, it does not explicitly discourage "mock reality" context. The following is one of the tasks in Kevin's worksheet:

Tshepo is $n$ years old. Mpho is twice as old as Tshepo will be in three years time. How old is Mpho, in terms of $n$ ?

The names used in this task are real and the task recruits the age comparison setting. However, the presence of the letter alphabet $n$ and lack of details in relation to setting suggest that the task is more about mathematics than the age comparison setting. The mathematical operation $(n+3) \times 2$ is an "exchange value" (Dowling, 1998:06) for an age comparison context. In this case, the mathematical operation ( + 3 ) $\times 2$ is presented as referring to something other than itself, the myth of reference (Dowling, 1998:6).

In presenting the solution of the task in the classroom, Kevin provided explicit rules on the way in which these tasks were to be engaged. He indicated to the learners that they would have to use letter symbols like $\mathrm{n}$ in terms of which the ages of Mpho and Tshepo could be determined. This process makes explicit what the teacher foregrounds, namely the mathematical procedures. Even though the context of age is recruited, it is clear that this only serves as a veneer for mathematical procedures. As shown in this snapshot interview with me (Godfrey); Kevin is conscious of the pseudo-realistic nature of the task:

Godfrey: In designing these word problems, does it matter what kind of answer the learners provide? For example, if they were to say 3 CD's cost R9.00 ${ }^{3}$

Kevin: (Repeats) If we said 3 CD's cost R9.00

Godfrey: The procedure: Yes, suggesting that $1 \mathrm{CD}$ costs R3.00. Would you be happy with that?

Kevin: Ehh...I'd probably want it to be a little more accurate but then you would have...I think quite often I use examples that would not be quite what you would expect. I want them to be able to pick up that three CD's costs this much and the way you get the price of one is that you divide by three. To me that's the important thing.

Renuka: The procedure

Kevin: (In agreement) the procedure

In his suggestion that he would want the answer to be a 'little more accurate' Kevin clearly sees the value of using the everyday context for the teaching of mathematics. He regards the acquisition of mathematical skills as more important, though. In fact, as is evident from the interview, that the context is trivial does not seem to strike him as significant. He prioritizes the induction of his learners to the art and language of a mathematical discourse and is less keen on raising issues of social concern. Could it be that he trades off these social issues for mathematical skills?

Having reflected on the different ways in which Bulelwa and Kevin manage the curriculum expectations with regard to the use of the everyday, the next section focuses on the implications that these two different approaches have with regard to their learners' mathematical competences.

\section{From pedagogy to mathematical knowledge}

It was indicated at the beginning that the epistemological position of the definition portrays mathematics as a unique subject with its own explicit grammar. Kevin's task and views are leaned towards supporting his learners gain access to this mathematics. The age comparison setting task is motivated more by mathematical interests than the everyday non-mathematical ones. Providing a rationale for his backgrounding of the everyday, Kevin highlighted, during the interview, that

...we are still linked to this matric syllabus...matric exam. If that changes, then I'll feel happy with a lot of stuff they are doing but

3 R9.00 is an unrealistic price for one CD let alone three CDs. 
they haven't changed that and what they are asking people to do now, that you will still be able to write the same matric exam. And I want someone to turn around and say, “... well, in the matric exam in 2005 this is what is going to be examined."

Kevin's approach is mainly influenced or shaped by the matric or Grade 12 mathematics syllabus. He sees himself as exposing learners to what is prioritized at Grade 12 level. In South Africa, the matric results receive considerable media publicity. There is thus an extent to which, albeit unintentionally, matric results serve as a marketing tool for most high schools. That Kevin seeks to align his teaching with matric maths requirements could be understood from this context. Thus, in spite of the expressed desire to recruit aspects of the everyday relevant to learners' experiences (when he introduced the lesson), Kevin finds himself having to accommodate and even foreground the mathematics.

Bulelwa's intentions to teach mathematical skills competes with (or is obscured by) her intentions to raise issues of social importance as suggested by the new curriculum. Her use of AIDS as a context, as well as the question on the prevention of AIDS implies that there is "a substantial residue of the nonmathematical setting which remains after the mathematical routines have run their course: (Dowling, 2000:9). The use of a meaningful context, it should be highlighted, is compatible with the pedagogic position of the definition as espoused in the Revised National Curriculum Statement. Bulelwa does not take this expectation lightly. With reference to AIDS as a context, Bulelwa emphasised during the interview:

I was actually concerned but the subject itself is a concern for debate. So even if there is somebody who has AIDS, I felt that it would enlighten them more, it would make them feel that you don't have to...(looks for the right phrase) it's a subject that we need to open up for debate. We need to discuss how it gets transmitted, for those who don't know about it yet. Because...in our community we still find people who are illiterate, who feel that there is no AIDS.

In spite (or because) of her passion and desire to implement what is advocated in the new curriculum, her students may be denied access to mathematics content knowledge.

\section{Who needs a realistic approach?}

The point the new South African Curriculum makes is that mathematics needs to be seen as a body of knowledge which is not devoid of human experiences. However, mathematics and the everyday are two different discourses and putting them in an "open relationship" may result in the dominance of one discourse over the other. This paper has highlighted, at a practical level, the experiences and challenges of two teachers in this respect. In no way can these experiences be regarded as general. However, the experiences of the two teachers provide some insights into the practical challenge of incorporating the everyday into mathematics. Summoning a range of their own resources as experienced teachers, Bulelwa and Kevin take up the challenge of incorporating the everyday into mathematics in two different ways.

Firstly, foregrounding the social aspects of the everyday, as was the case in Bulelwa's class, seemed to render the mathematics invisible or inaccessible. In other words, the meaningfulness of the context in relation to the lives and experiences of the teacher and learners may render the context so visible that the mathematics may not be accessed. Secondly, foregrounding the mathematical goals, as was the case in Kevin's class, may motivate teachers to recruit what may be considered dead-mock reality. In other words, the everyday may solely be treated as a sugar-coat for or vehicle towards mathematics. In real life, for example, no David or Mary can be of age $n$ or $n+1$.

These experiences help us appreciate the practical challenge of incorporating the everyday into mathematics. Instead of regarding Bulelwa and Kevin as having "succeeded" or "not succeeded," we should appreciate that the task of making mathematics relevant is a challenging one. The expectation that the incorporation of the everyday into mathematics will occur unproblematically seems simplistic.

\section{References}

ADLER, J., 2000, “Conceptualising resources as a theme for mathematics teacher education" in Journal of Mathematics Teacher Education, 4 (1), May

BERNSTEIN, B., 1996, Pedagogy, symbolic control and identity: Theory, Research Critique London: Taylor and Francis. 


\section{Godfrey Sethole}

CLARKE, D.J., 2001, Application to conduct research summary: Learners' Perspective Study (Unpublished Report)

COOPER, B. \& DUNNE, M., 2000, Assessing children's mathematical knowledge: Social class, sex and problem-solving, Open University Press: Buckingham

Department of Education, 2001, Revised National Curriculum Statement for Mathematics, Department of Education: Pretoria

DOWLING, P., 1998, The sociology of mathematics education: Mathematical Myths/Pedagogic Texts, Falmer Press: London

FLODEN, R.E., BUCHMAN, M.\& SHWILLE, R.J., 1987, Breaking with everyday experience, Summer 88(4)

FREUDENTHAL, H., 1973, Mathematics as an educational task, D Reidel Publishing Company: Holland

MUKHOPADHAY, S., 1998, "When Barbie Goes to Classrooms: Mathematics in Creating a Social Discourse" in C. Keitel (Ed.) Social justice and mathematics Education: Gender, Class, Ethnicity and Politics of schooling pp. 150 - 161

MULLER, J. AND TAYLOR, N., 1985, "Schooling and everyday life: knowledges sacred and profane" in Social Epistemology 9 (3), pp. 257-75
NYABANYABA, T., 1999, "How 'real' is 'relevance?' Tensions emerging in teachers' talk within and about relevance," in Pythagoras, 48, pp. $17-25$

SALJO, R. \& WYNDAHMN, F., 1993, "The school as a context for problem solving” in S. Chanklin and J. Lave Understanding Practice, New York: Cambridge University press, pp. 327 - 343

SETATI, M., 2002, Unpublished PHD dissertation, University of the Witwatersrand

SKOVSMOSE, O., 1994, Towards a philosophy of critical education, Kluwer Academic publishers: Dordrecht

TAYLOR, N., 1999, “Curriculum 2005: Finding a balance between the everyday and school knowledges” in N. Taylor and P. Vinjevold. (Eds.), Getting Learning Right. Joint Education Trust: Johannesburg

VOLMINK, J., 1994, "Mathematics by all" in S. Lerman (Ed.) Cultural Perspectives on the Mathematics Classroom, Kluwer Academic Publishers: Dordrecht

VITHAL, R. et al, 1997, "Student teachers doing project work in primary mathematics classrooms" in P. Kelsall \& M de Villiers (Eds.) Proceedings of the Third National Congress of AMESA, pp. 261 276 